\title{
SPubsaúde
}

\section{Tratamento Estético para Acne Vulgar}

\author{
Aesthetic Treatment for Acne Vulgaris
}

\author{
Vicente Alberto Lima Bessa ${ }^{1}$, Maria Fátima de Sousa Bessa ${ }^{2}$, Vanessa Teixeira Paula Moraes $^{3}$ \\ ${ }^{1}$ Centro Universitário Celso Lisboa. Rio de Janeiro, RJ, Brasil. "2Prefeitura do Municipal do Rio de Janeiro. Rio de Janeiro, RJ, Brasil. \\ ${ }^{3}$ Centro Universitário Celso Lisboa. Rio de Janeiro, RJ, Brasil. *Autor para correspondência: vicente.bessa@bol.com.br
}

\begin{abstract}
Resumo: 1. Introdução: O estudo teve como objetivo geral investigar as principais condutas de tratamento estético para pessoas com acne vulgar. As informações obtidas nas bases de dados Scielo, Medline-PubMed e Google Scholar foram escolhidas e organizadas no formato de uma revisão sistemática a partir da análise de periódicos originais e de revisão publicados entre 2015 e 2019. 2. Revisão: A acne é o principal diagnóstico das consultas dermatológicas de acordo com Sociedade Brasileira de Dermatologia (2018) e seu agente etiológico é a Cutibacterium acnes e seu tratamento estético se faz necessário para se evitar cicatrizes inestéticas e danos psicológicos. 3. Discussão: O esteticista pode intervir nos dois primeiros graus sem acompanhamento médico e, para tanto, ele possui um arsenal terapêutico que envolve recursos fotoeletroterapêuticos e cosméticos. 4. COnsiderações Finais: Os tratamentos eletroterapêuticos mais recomendados pelos seus resultados satisfatórios são: microcorrente, iontoforese, LED, radiofrequência, microagulhamento e os cosméticos podem ser associados.
\end{abstract}

Palavras-chave: Propionibacterium acnes, Cutibacterium acnes, acne vulgaris.

\begin{abstract}
Introduction: The aim of this study was to investigate the main aesthetic treatment conducts for people with acne vulgaris. The information obtained from the Scielo, Medline-PubMed and Google Scholar databases was chosen and organized in the form of a systematic review based on the analysis of original and review journals published between 2015 and 2019. 2. Review: Acne is the main diagnosis of dermatological consultations according to the Brazilian Society of Dermatology (2018) and its etiological agent is Cutibacterium acnes and its aesthetic treatment is necessary to avoid unsightly scars and psychological damage. 3. Discussion: The beautician can intervene in the first two degrees without medical supervision and, therefore, he has a therapeutic arsenal that involves photoelectrotherapeutic and cosmetic resources. 4. Final Remarks: The most recommended electrotherapeutic treatments for their satisfactory results are: microcurrent, iontophoresis, LED, radiofrequency, micro-needling and cosmetics may be associated.
\end{abstract}

Keywords: Propionibacterium acnes, Cutibacterium acnes, acne vulgaris.

\section{Introdução}

A acne vulgar é uma doença dermatológica muito prevalente em adolescentes, mas pode persistir na vida adulta. Ela se caracteriza pela presença de processo inflamatório das glândulas sebáceas e dos folículos pilossebáceos com formação de comedões, pústulas, pápulas e outras lesões elementares na pele.

Ela gera uma aparência inestética e por ser frequente na adolescência, período de grandes mudanças hormonais e formação da personalidade, ela pode comprometer o estado psicológico. Existem pessoas que ficam angustiadas, sofrem impacto nas interações sociais, desenvolvem baixa autoestima e pode afetar até mesmo a capacidade de obter emprego (Hession \& Graber, 2015)

Conquanto a acne não seja uma doença contagiosa e tenha caráter benigno, ela pode deixar cicatrizes inestéticas extremamente difíceis de serem tratadas ou amenizadas. Logo, o tratamento precoce se faz necessário para preservar a saúde da pele e a saúde mental da pessoa.

O tratamento da acne vulgar pelo profissional da estética tem a finalidade de manter a pele limpa e saudável, livre de comedões e pústulas, inibir a proliferação bacteriana e a inflamação e prevenir a formação de cicatrizes inestéticas. Há diversos tratamentos que podem ser empregados, dependendo do grau da acne e das condições gerais da pele. Para tanto, foi desenvolvido este estudo cujo objetivo geral foi investigar as principais condutas de tratamento estético para pessoas com acne vulgar. Foram traçados os seguintes objetivos específicos: descrever a fisiopatologia da acne, bem como suas causas; classificar os graus de acne correlacionados com as repercussões na pele; determinar as condutas de tratamento estético elegíveis para pessoas com acne vulgar. 
Para investigar os objetivos de estudo foi realizada uma revisão sistemática a partir da análise de periódicos originais e de revisão publicados entre 2015 e 2019, em idioma português e inglês. A busca foi realizada nas bases de dados da Scielo, Medline-PubMed e Google Scholar através dos descritores Propionibacterium acnes, Cutibacterium acnes, acne vulgaris.

O presente estudo se justificou pela alta prevalência da acne vulgar na população e a necessidade de intervenção precoce, visto que o profissional de estética atua nas fases iniciais da acne, ou seja, graus I e II. Logo, conhecer e divulgar os procedimentos de tratamentos estéticos é imperioso para a melhor formação dos futuros esteticista.

\section{Revisão}

O tegumento humano, mais conhecido como pele, é um órgão vital que funciona como um invólucro corporal ligado à saúde da pessoa. Ele tem funções estética, imunológica, de proteção química, física e biológica e é constituído por duas camadas distintas, a epiderme e a derme. Na epiderme existe uma rica flora microbiana que é formada especialmente por três gêneros de bactérias denominadas de Corynebacteria acnes, Propionibacterium acnes (P. acnes) e Staphylococcus. É imperioso ressaltar que em circunstâncias normais essas bactérias não são patogênicas, mas essenciais para manter a pele saudável, pois evitam a colonização de outras bactérias nocivas. Todavia, a P. acnes durante a desregulação da homeostase cutânea pode atuar como patógeno oportunista para o desenvolvimento da acne vulgar (Dréno et al., 2018).

É sabido que a P. acnes é a bactéria lipofílica mais predominante na pele rica em sebo e desempenha papel importante na patogenia da acne vulgar. Acredita-se que a ocidentalização aumentou o predomínio da $P$. acnes na microbiota cutânea humana quando comparado ao de estilo de vida de populações naturais. Por isso, as mudanças socioeconômicas e de estilo de vida podem desequilibrar a delicada simbiose e transformar uma espécie inofensiva em um patógeno oportunista. É possível constatar esse fenômeno da disbiose bacteriana na patogênese da acne (Szabó et al., 2017).

Porém, é bom destacar que a $P$. acnes não é o gatilho para a acne vulgar, mas sim uma consequência do desequilíbrio da microbiota cutânea que está relacionada a outras alterações, tais como: aumento da produção sebácea e modificação de sua composição, hipercornificação do folículo pilossebáceo. Além disso, há outros fatores que podem contribuir para a acne, tais como: os fatores ambientais, hormônios, histórico familiar e estresse (Dréno et al., 2018).

Classificação da acne vulgar não é universal, sendo que a forma mais utilizada para classificá-la leva em consideração a descrição dos tipos e extensão das lesões. E assim é que se pode definir o seu grau de gravidade e orientar nas condutas terapêuticas. Ela pode ser classificada em cinco graus de gravidade. Em sua fase inicial é branda e há comedões, com a progressão surgem as pápulas, pústulas, nódulos, fístulas, crostas hemorrágicas, artralgia e febre (Agostinho, 2017). A seguir é possível verificar a classificação e as características da acne vulgar no Quadro 1 e o seu aspecto visual na Imagem 1.

Quadro 1. Classificação e características da acne vulgar.

\begin{tabular}{|c|l|l|}
\hline Grau & \multicolumn{1}{|c|}{ Tipo } & \multicolumn{1}{c|}{ Descrição } \\
\hline I & Acne comedônica & $\begin{array}{l}\text { Inicia-se a lesão inflamatória com presença de comedões fechados e comedões } \\
\text { abertos e }\end{array}$ \\
\hline II & Acne papulopustulosa & $\begin{array}{l}\text { Há presença de comedões acompanhados de pápulas (lesões sólidas) com ou sem } \\
\text { eritema e pústulas (lesões líquidas de conteúdo purulento) e seborréia sempre } \\
\text { presente. }\end{array}$ \\
\hline III & $\begin{array}{l}\text { Acne nódulo-abscedante ou } \\
\text { nódulo-cística }\end{array}$ & $\begin{array}{l}\text { Há presença de comedões, pápulas com ou sem eritema, pústulas, seborréia e nódulos } \\
\text { (lesões sólidas mais exuberantes). }\end{array}$ \\
\hline IV & Acne conglobata & $\begin{array}{l}\text { Há presença de comedões, pápulas com ou sem eritema, pústulas, seborréia, nódulos } \\
\text { purulentos, abscessos e fístulas. Este tipo de acne deixa cicatrizes significativas. }\end{array}$ \\
\hline V & Acne fulminante & $\begin{array}{l}\text { É a forma mais severa de acne e apresenta sintomas sistêmicos como fadiga, mal- } \\
\text { estar, mialgias, artralgia e febre. Além de apresentar o quadro clínico característico } \\
\text { da acne grau IV, com nódulos inflamatórios e crostas hemorrágicas. }\end{array}$ \\
\hline
\end{tabular}

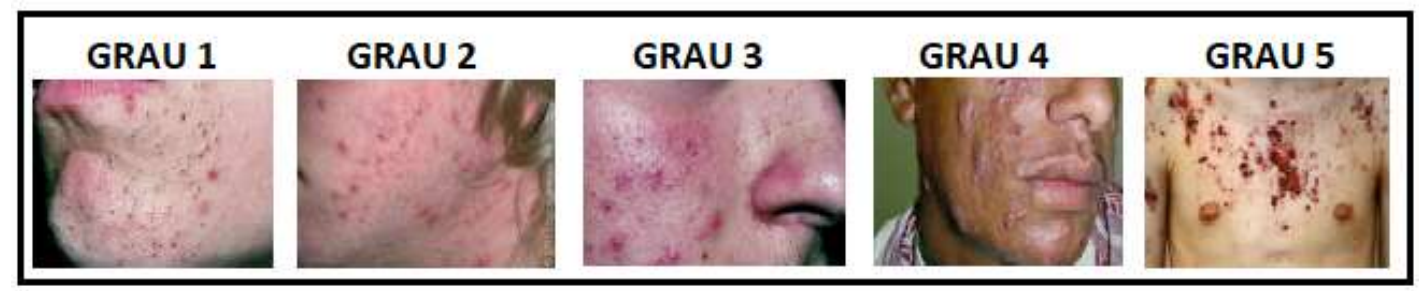

Imagem 1. Classificação da acne vulgar. Fonte: Agostinho, 2017. 
A acne vulgar é diagnosticada pelo médico através de exame clínico e pode receber tratamento medicamentoso ou apenas tratamentos estéticos. Dentre eles, os tratamentos eletroterapêuticos mais recomendados são: microcorrente, iontoforese, LED, radiofrequência, microagulhamento e estes podem se associados aos cosméticos.

\section{Discussão}

A $P$. acnes é classificada como uma espécie de bactéria anaeróbica gram-positiva do gênero Corynebacterium que pertencente ao filo de Actinobacteria. Ela é aerotolerante e reside na parte mais interna do folículo sebáceo em contato com queratinócitos, embora também seja encontrada na superfície da pele. No entanto, é mais comum a presença do Staphylococcus epidermidis na superfície da pele (Dréno et al., 2018).

$\mathrm{O}$ crescimento da $P$. acnes é lento e ela se alimenta do sebo produzido pelas glândulas sebáceas, mas o aumento da secreção sebácea pode gerar uma ambiente favorável ao seu desenvolvimento (Bagatin et al., 2019). Quando a $P$. acnes se coloniza em excesso, o organismo responde com um processo inflamatório gerando as chamadas acnes, comumente conhecidas como "espinhas".

O genoma da bactéria foi sequenciado e foi proposta uma reclassificação de Propionibacterium acnes para Cutibacterium acnes (C. acnes). A proposta considerou a sequência gênica que permite que novas espécies sejam qualificadas pela homologia da sequência do gene 16S rRNA. A reclassificação tem consistência com os habitats das espécies, topologia genômica, conteúdo de DNA G + C e composição do peptidoglicano (Scholz \& Kilian, 2016). A reclassificação baseada em investigações bioquímicas e genômicas são importantes porque permitem novas estratégias inovadoras focalizadas nos biofilmes de $C$. acnes e/ou em seus filotipos associados à acne (Dréno et al., 2018).

A C. acnes se adaptou para gerar enzimas degradantes para a pele, o triacilglicerol lipase e o lisofosfolipase, que metabolizam os triglicerídeos no sebo. A sua reclassificação tornou-se necessária para diferenciá-la de outras espécies ambientais de Propionibacteria que estão presentes nos produtos lácteos e rúmen de gado (Scholz \& Kilian, 2016). É bom frisar que a degradação dos triglicerídeos no sebo produz os ácidos graxos de cadeia curta, em especial, o ácido propanóico que é importante para a manutenção do pH ácido da pele (Dréno, 2018).

A acne é uma doença de pele que embora não seja fatal pode persistir por anos e causar graves impactos psicossociais. Ela afeta principalmente a face, mas também pode se disseminar pelo pescoço, tórax, braços etc., e possui a possibilidade de deixar lesões cicatriciais e até desfigurações. Logo, ela está presente em uma região difícil de ser escondida, o que pode provocar frustração, diminuição da autoestima, retraimento social e depressão.

A acne vulgar é uma dermatose muito comum que afeta a população em geral, prioritariamente os adolescentes, com uma taxa de prevalência de $85 \%$ em indivíduos entre 12 e 24 anos. Embora ela seja típica na adolescência, tem sido constatado o aumento da sua incidência na população adulta, notadamente em mulheres (Ribeiro et al., 2015).

Portanto, a acne vulgar é prevalente em adolescentes, porém ela tem aumentado em adultos entre 20 e 30 anos e passa a ter um declínio gradual com a idade. Acredita-se que a prevalência crescente em adultos poderia ser justificada pela maior conscientização das pessoas e consequente aumento no número de registro de casos (Costa \& Velho, 2018).

Em 2018, a Sociedade Brasileira de Dermatologia realizou um estudo sobre o perfil nosológico das consultas dermatológicas. Participaram do estudo 885 dermatologistas que correspondente a 10\% dos membros na época. Foram coletados e analisados dados de 9629 consultas, sendo a maioria do sexo feminina $(68,6 \%)$ e caucasiana. O principal diagnóstico das consultas dermatológicas foi a acne $(\mathrm{n}=771)$ que correspondeu a $8 \%$. Em seguida, o fotoenvelhecimento com 7,7\%, câncer de pele não melanoma com 6,6\%, queratose actínica com $4,7 \%$, micoses superficiais com $4,5 \%$ e as demais doenças em menos percentual. Quanto à faixa etária, $48,4 \%$ dos pacientes tinham entre 13 e 24 anos e foi confirmado o diagnóstico de acne. Em relação à cor de pele, a acne ocupa o $3^{\circ}$ lugar no rank, atrás do fotoenvelhecimento e câncer de pele não melanoma em pessoas com cor branca. Já pessoas com cor não branca, acne ocupou o $1^{\circ}$ lugar no rank, seguida pela micose superficial e melasma. Quanto à distribuição por sexo, a acne ocupa o $1^{\circ}$ lugar no rank para os homens, seguido do câncer de pele não melanoma. Para as mulheres, ela está no $2^{\circ}$ lugar atrás do fotoenvelhecimento (Miot et al., 2018).

Existe um tipo de acne que se distingue da acne vulgar, ela é denominada de acne feminina adulta (AFA), pois ela persiste até o período pós-menopausa. A AFA acomete mulheres acima de 25 anos e pode persistir desde a adolescência, logo ela representa um desafio, pois tem tendência à recidiva mesmo com tratamentos com antibióticos orais ou isotretinoína (Bagatin et al., 2019). 
A acne vulgar é uma dermatose crônica e imunomediada que acomete a folículo pilossebáceo (Ribeiro et al, 2015). Ela é multifatorial, pois há interação complexa de fatores como: alteração hormonal androgênica, predisposição genética, hipersecreção sebácea levando à produção exagerada de sebo, alteração da composição do sebo, aumento da queratinização folicular levando à formação dos comedões abertos e fechados, alterações na flora microbiana e inflamação dérmica periglandular (Bagatin et al., 2019; Ribeiro et al., 2015). Há outros fatores podem contribuir para o desenvolvimento da acne, tais como: medicamentos, ingestão de alimentos de alta carga glicêmica, ingestão de iodo, leite (Bagatin et al., 2019; Ribeiro et al., 2015), suplementos alimentares ricos em aminoácidos de cadeia ramificada (Ribeiro et al, 2015), tabagismo e estresse (Bagatin et al., 2019; Costa \& Velho, 2018).

A fisiopatologia da acne vulgar envolve diversos conceitos antigos e alguns novos, como principalmente o agente etiológico envolvido, o $C$. acnes, e o processo inflamatório. Há vários fatores que interagem para o desenvolvimento da acne e basicamente quatro estão presentes: hipersecreção sebácea, hiperqueratinização do folículo pilossebáceo, colonização bacteriana e liberação de mediadores inflamatórios no folículo e na derme adjacente (Ribeiro et al., 2015).

As glândulas sebáceas são glândulas microscópicas presentes na pele e são responsáveis por secretar uma substância oleosa denominada sebo, o qual lubrifica e impermeabiliza a pele e os pelos nos seres humanos. $\mathrm{O}$ sebo é uma mistura rica em lipídios, tais como os triglicerídeos, ácidos graxos, colesterol, ésteres e escaleno (Ribeiro et al., 2015).

O estímulo da glândula sebácea está diretamente regulado por andrógenos. Dentro da glândula sebácea, a ação das enzimas 3-beta-hidroxiesteroide-desidrogenase, 17-hidroxiesteroide-desidrogenase e 5-alfaredutase convertem os andrógenos sulfato de de-hidroepiandrosterona e a androstenediona em andrógenos mais potentes denominados testosterona e di-hidrotestosterona. Por sua vez, há o aumento da resposta da glândula sebácea à estimulação hormonal com aumento na produção de sebo (Ribeiro et al., 2015).

A hipersecreção de sebo facilita a proliferação da $C$. acnes que fazem a hidrólise dos triglicerídeos presentes no sebo em ácidos graxos livres. Esses ácidos podem irritar a parede do folículo pilossebáceo que colaboraria para a proliferação anormal de queratinócitos gerando a hiperqueratose (estágio inicial da comedogênese). A C. acnes e a hipersecreção sebácea são reconhecidas pela imunidade inata através da ativação de receptores Toll-like ou TLR 2 e 4 e desta forma, há liberação de citocinas pró-inflamatórias, como a interleucina-1 alfa. Nos estágios iniciais da acne também há a formação de infiltrado mononuclear constituído por linfócitos T CD4 + e macrófagos CD68 + (Bagatin et al., 2019).

Com o aumento da taxa de secreção sebácea, tem-se o decréscimo na concentração de ácido linoléico que é um ácido graxo essencial que protege a parede epitelial da glândula sebácea. A radiação ultravioleta combinada com a C. acnes gera peroxidação do esqualeno, cujos subprodutos têm ação comedogênica. Todos esses fenômenos em conjunto causam danos ao epitélio e aumentam a queratinização infundibular e a inflamação dérmica (Bagatin et al., 2019).

Atualmente, se considera que a inflamação está presente como protagonista em todas as fases da formação da acne, assim como a presença de linfócitos T CD4+, macrófagos e o aumento da interleucina 1 em folículos pilossebáceos precede o processo de hiperqueratinização. Por outro lado, é a colonização da $C$. acnes que leva a inflamação, logo é considerada a principal responsável pela patogênese da acne vulgar (Ribeiro et al., 2015).

A C. acnes produz enzimas denominadas lipases, proteases, hialuronidases, endoglycoceramidase, sialidase/neuroaminidase, proteinases e os fatores 5 Camp. Essas enzimas contribuem para a degradação tecidual e estimulam a resposta inflamatória, além de serem capazes de romper os comedões (Ribeiro et al, 2015). Quando os comedões são rompidos o material folicular é disperso na derme e não na superfície da pele. Dependendo do dano na pele, promovido pelos comedões, irão surgir diversos tipos de lesões inflamatórias, como pápulas, pústulas, nódulos e/ou cistos. Portanto, ela pode causar lesões não inflamatórias (comedões abertos e fechados) ou lesões inflamatórias (pápulas, pústulas e nódulos) em graus distintos de cicatrização (Tan, Schlosser, \& Paller, 2018).

É necessário destacar que a acne vulgar não pode ser considerada como uma doença infecciosa, visto que a $C$. acnes está normalmente presente na pele e apenas desencadeia a doença quando encontra um terreno dermatofisiológico favorável. Portanto, o papel da C. acnes é mais inflamatória do que infecciosa.

A acne vulgar pode ser diagnosticada pelo médico através de exame clínico e em sua fase inicial não são necessários exames complementares. Quando há suspeita de hiperandrogenismo é indispensável à investigação de doenças como: síndrome dos ovários policísticos, hiperplasia adrenal congênita, tumores ovarianos ou de suprarrenais. Pode ser necessária a realização de exames de sulfato de deidroepiandrosterona, testosterona total e 17a-hidroxiprogesterona (Agostinho, 2017). A investigação laboratorial em mulheres adultas com acne pode ser feita com os exames de hormônio folículo estimulante e hormônio luteinizante, 
além dos anteriormente citados. Em caso de suspeita de síndrome do ovário policístico é feita a ecografia transvaginal para visualização dos ovários (Bagation et al., 2019).

É mister frisar que o ideal é tratar a acne precocemente, pois a concepção de que ela desaparecerá com a idade é inadequada. A demora no tratamento pode agravar a acne ou deixar cicatriz pós-inflamatória. O controle da acne é essencial não só por questões estéticas, mas para preservar a integridade da pele, a saúde psíquica, além de evitar cicatrizes complexas de corrigir ou amenizar. Embora a acne possa ser curada ou controlada, o tratamento pode ser bastante prolongado e o cliente deve estar ciente deste fato.

Algumas orientações podem ser feitas pelo profissional da estética ao cliente para evitar complicações da acne. O cliente não deve manipular as lesões ("espremer"), pois corre o risco de infectar, inflamar ou deixar cicatrizes. Além de ser recomendado usar produto de higiene para pele acneica ou oleosa, todavia a limpeza excessiva pode ser prejudicial à pele, pois pode causar irritação ou agravar as lesões. A acne pode melhorar quando a pessoa é exposta moderadamente ao sol, porém a exposição excessiva tende a piorar o quadro. De qualquer forma, o uso protetor solar (UVA, UVB e luz visível) é um procedimento ímpar, ou seja, indispensável.

As condutas de tratamento médico envolvem medicações de uso tópico, antibióticos orais e até o uso da isotretinoína. As principais medicações de uso tópico são: os retinoides (adapaleno e tretinoína); antibióticos tópicos (clindamicina e eritromicina); peróxido de benzoíla. Porém, pode ser necessário o uso de medicamentos sistêmicos, tais como: tetraciclina e doxiciclina. E em alguns casos é necessária a terapia antiandrogênica, como: etinilestradiol com progestágeno antiandrogênico como acetato de ciproterona, desogestrel ou drospirenona (Agostinho, 2017).

As condutas estéticas para o tratamento da acne são diversificadas e a sua seleção dependerá, principalmente, do grau de gravidade da acne. É bom destacar que o esteticista poderá atuar sem supervisão médica não casos de acnes graus I e II, mas em casos mais graves só poderá atender sob orientação e/ou supervisão médica. A acne grau $\mathrm{V}$ é de exclusividade médica, pois a pessoa corre até risco de vida, porém as sequelas podem ser tratadas pelo esteticista, a fim de minimizar as cicatrizes pós-inflamatórias.

Um dos primeiros passos para iniciar o tratamento da acne pelo esteticista é a limpeza de pele, a qual só poderá ser executada pelo profissional, ou seja, nunca deve ser realizada por leigos. Ela é um procedimento básico essencial para preparar a pele para o tratamento da acne através de cosméticos e recursos fotoeletroterápicos. Ela é uma conduta de higienização profunda que objetiva retirar as sujidades superficiais e profundas, remover a oleosidade, além de retirar os conteúdos cutâneos que obstruem os folículos pilossebáceos que levam a afecções inestéticas como pápulas e pústulas.

É evidente que quaisquer procedimentos estéticos devem atender as normas de biossegurança, mesmo para um procedimento simples como a limpeza de pele. O passo a passo da sequência básica da limpeza de pele envolve a higienização, esfoliação, emoliência, extração, desinfecção, máscara cosmética, tonificação e finalização com protetor solar.

A limpeza de pele é iniciada pela higienização da pele que visa remover as impurezas como os resíduos de poluição, suor, oleosidade, maquiagem, cosmético e protetor solar. Se a cliente estiver usando maquiagem é recomendado iniciar a higienização com um demaquilante seguido de um gel ou sabonete líquido. Caso, não use maquiagem é possível iniciar a higienização com aplicação do um gel ou sabonete líquido neutro ou específico para pele oleosa e acneica.

Junto com a higienização ou após ela, será feita a esfoliação cujo principal objetivo é a remoção das células mortas da camada córnea. Dependendo do grau da acne, a esfoliação deve ser feita com menor pressão contra a pele e de preferência em movimentos circulares ou retilíneos. Sempre se deve retirar o excedente do produto com os próprios dedos, bandeletes ou lenço facial.

Caso a pele se mantenha oleosa após a higienização e esfoliação, recomenda-se aplicar o desincruste que é um tipo de eletroterapia. O desincruste possui uma ação eletroquímica quando associado a uma substância desincrustante e permite retirar de forma suave os sebos incrustados na superfície epidérmica. O equipamento utiliza uma corrente galvânica com o eletrodo ativo em forma de gancho que é envolto em alguma substância desincrustante. Já o eletrodo passivo, em forma de placa de silicones, é colocado na região posterior do ombro ou braço para fechar o circuito elétrico. As principais substâncias desincrustantes possuem sódio na sua composição, tais como: lauril sulfato de sódio, sulfato de sódio, salicilato de sódio, cloreto de sódio, carbonato de sódio, etc.

Higienizada e esfoliada a pele, aplica-se um emoliente que contém ativos que reduzem a resistência da pele, dilatam os óstios e amolecem a superfície da pele, o que facilita a extração dos comedões e das pústulas. O emoliente deve ser aplicado na pele por cerca de 10 minutos ou de acordo com recomendação do fabricante. Ele precisa ser removido gradualmente conforme a evolução da extração. 
O profissional pode acrescentar na etapa da emoliência recursos que promovam o aquecimento da região e melhorem a dilatação dos folículos e facilitem a extração. Os dois recursos mais utilizados são: vapor de ozônio e máscara térmica. Todavia, a seleção do recurso deverá considerar a preferência do cliente e as possíveis contraindicações. Em média o tempo de aplicação desses recursos é de 5 a 10 minutos.

Com o amolecimento dos comedões e dilatação dos folículos, a extração pode ser efetuada. A habilidade e o treino do profissional são importantes para evitar desconforto durante a extração, além do mínimo de dor, vermelhidão, sangramento e hipersensibilidade tecidual. A extração somente deve ser feita nos comedões e pústulas, não sendo possível extrair as pápulas, cistos, nódulos e abscessos. Após a extração, tem-se a desobstrução dos folículos pilossebáceos e este fato potencializa a permeação de princípios ativos pelas vias transanexiais. A extração aumenta a oxigenação do tecido, facilita a transpiração e lubrificação superficial e melhora a formação do manto hidrolipídico (Borges \& Scorza, 2016).

A desinfecção da pele após a extração pode ser feita com cosméticos que tenham funções antissépticas e anti-inflamatórias ou com aplicação da alta frequência. A alta frequência permite benefícios ímpares, pois além de efeito antimicrobiano sobre vírus, fungos e bactérias, acelera o processo de cicatrização de feridas cutâneas, melhora da oxigenação e nutrição tissular graças ao seu efeito vasodilatador superficial, além de ter efeito anti-inflamatório e analgésico (Bessa, 2019).

Após a desinfecção é possível ser aplicada uma máscara facial que pode conter ativos adstringentes, secativos, antissépticos e anti-inflamatórios concomitantemente, além de ativos calmantes e suavizantes. As máscaras calmantes são sempre recomendadas devido à hipersensibilidade que pode aparecer em função do atrito contra a pele durante a extração.

A aplicação de um tônico é recomendada para fazer a correção do $\mathrm{pH}$ da pele e normalizar os poros e óstios que estão dilatados em função dos procedimentos anteriores. Pode-se tirar o excesso da mascará com um bandelete umedecido no tônico. E a finalização é feita com aplicação de filtro com fator de proteção solar UVA, UVB, IV e luz visível, livre de óleo, o qual é específico para pele lipídica.

A limpeza de pele pode ser considerada um tratamento inicial ou um pré-tratamento para pele acneica. $\mathrm{O}$ tratamento estético é mais prolongado e envolvem várias sessões com utilização de cosméticos específicos, recursos fotoeletroterapêuticos, além de tratamentos para amenizar as cicatrizes pós-inflamatórias deixadas pelas acnes. Os principais recursos fotoeletroterapêuticos utilizados no tratamento da acne ou das cicatrizes acneicas, são: a microcorrente, iontoforese, LED e radiofrequência, além do microagulhamento que não é um procedimento fotoeletroterapêuticos.

A microcorrente é uma eletroterapia de baixa frequência que distribui os impulsos elétricos na área a ser tratada e possui uma corrente elétrica biocompatível. Ela pode ser empregada no tratamento da acne, pois acelera os processos regenerativos naturais do corpo, melhora circulação sanguínea e linfática, estimula a produção de colágeno e elastina, reduz a vermelhidão e a inflamação.

Ela é uma terapia promove a melhora da vascularização e estimula a proliferação dos fibroblastos e estes fazer síntese de colágeno. Ela também aumento da permeabilidade das membranas celulares e normaliza a bioeletricidade tecidual, aumenta em até $500 \%$ a produção do trifosfato de adenosina, logo facilita a regeneração do tecido (Martelli, 2016). Por todos os efeitos descritos, justifica-se o emprego da microcorrente para tratar a acne.

A iontoforese ou ionização é outro tipo de eletroterapia que consiste em um método de administração de substâncias através da pele, que utiliza corrente elétrica para promover a permeação transdérmica. Ela emprega uma corrente contínua (galvânica) que repele íons da mesma polaridade existente no eletrodo ativo para a pele, ou seja, os íons diferentes se atraem e os íons iguais se repelem. Logo, se no princípio ativo predominar uma carga iônica positiva, ele será aplicado no eletrodo ativo (positivo), a fim de facilitar o drug delivery. Se no princípio ativo predominar uma carga iônica negativa, ele será aplicado no eletrodo ativo (negativo).

A pele possui um pH ácido, características hidrofóbicas e uma matriz lipoproteica, por isso o cosmético possui dificuldades em penetrar na pele por difusão passiva. Para facilitar a permeação é possível usar a corrente contínua, especialmente daqueles que contêm substâncias hidrofílicas e ionizáveis (Borges \& Scorza, 2016). A iontoforese é muito recomendada no tratamento da pele acneica por facilitar a permeação do ativo de forma mais eficiente.

Diodo emissor de luz ou Light Emitter Diode (LED) é um tipo de fototerapia que emite uma luz cintilante na pele gerando fenômenos de fotobioestimulação que geram uma cascata de respostas celulares resultando na modulação da função celular, proliferação celular e reparação das células comprometidas. Há vários tipos de LED de acordo com seu comprimento de onda de 405nm (luz visível azul) a 940nm (infravermelho). Sendo que o LED azul mais recomendado para tratar a acne por ter ação bactericida, oxigenante e cicatrizante. 
A utilização do LED azul ou azul-vermelho representa um avanço significativo tratamento das lesões inflamatórias leves a moderadas da acne. Essas fontes de luz também podem ser aplicadas conjugadas com medidas farmacológicas e/ou físicas para otimizar o resultado terapêutico. O LED azul tem efeito bactericida, interrompe a função da glândula sebácea e exerce efeitos anti-inflamatórios. Há estudos que comprovam que a acne tratada com a luz azul-vermelha tem uma melhora em torno de $76 \%$ quando comparada com peróxido de benzoílo ou luz azul sozinha. Assim como tratamentos com LED azul, azul-vermelho ou radiação infravermelha apresentaram melhores resultados quando comparados ao LED amarelo, verde ou vermelho. Este tipo de tratamento é seguro, eficaz e apresenta complicações mínimas ou inexistentes, porém ainda não há informações suficientes para determinar dosagem e o número ideais de sessões necessárias o tratamento da acne (Pei, 2015).

A radiofrequência é um equipamento que emite oscilações eletromagnéticas na faixa de frequência que abrange aproximadamente de $3 \mathrm{kHz}$ a $300 \mathrm{GHz}$. A passagem da radiofrequência aquece o tecido e o calor acelera as reações químicas do organismo, logo atua como um catalisador de todas as reações enzimáticas da síntese protéica e da atividade metabólica, promovendo a neocolagênese e estreitando o tecido cutâneo. Ela é um procedimento seguro e eficaz para tratar as cicatrizes de acne (Oaigher \& Blanco, 2016).

Uma pesquisa de estudo de casos retrospectivos foi realizada para comparar a segurança e a eficácia em longo prazo da terapia de radiofrequência fracionária bipolar como tratamento para cicatrizes de acne atróficas e acne vulgar. Oito voluntários com acne atróficas de leve a grave foram submetidos a cinco sessões de radiofrequência fracionária com intervalos de um mês. Os participantes foram acompanhados por pelo menos um ano após o tratamento final. E pode-se concluir que o tratamento foi eficaz, pois as cicatrizes atróficas leves responderam 50\% melhor que as moderadas e graves. Exames de biópsia constataram uma diminuição das unidades pilossebáceas da derme e infiltrados de células inflamatórias perivasculares, além de um aumento no conteúdo de elastina e deposição de colágeno na derme superior (Kaminaka, Furukawa, \& Yamamoto, 2016).

A radiofrequência fracionada pode ser empregada no tratamento das cicatrizes de acne. Para tanto, um estudo foi realizado com 20 voluntários de ambos os sexos, com idades de 16 a 60 anos, com pele do tipo IV e V na escala de Fitzpatrick e com cicatrizes de acne moderada a grave. Eles foram submetidos a sessões de radiofrequência nanofracionada com 3 a 6 intervalos semanais e foram avaliados através de fotografias em cada consulta e até 6 meses após a sessão final de tratamento. O estudo permitiu concluir que a radiofrequência nanofracionada produziu melhoria cosmética das lesões de cicatrizes de acne na pele facial com grau elevando de satisfação (Goel \& Gatne, 2017).

Dentre os tratamentos para amenizar as cicatrizes pós-inflamatórias da acne, tem-se a Indução Percutânea de Colágeno por Agulhas (IPCA), também conhecida por microagulhamento. A IPCA consiste em realizar microperfurações da pele com finas agulhas estéreis metálicas, cujo principal resultado é a indução de colágeno, além de outras fibras naturais na pele, bem como o espessamento da epiderme. A técnica pode ser aplicada por rollers, canetas elétricas ou carimbos e sem reutilização deles. Ela é considerada uma técnica minimamente invasiva que pode ser aplicada pelo esteticista habilitado. É recomendada para tratar as cicatrizes, especialmente as de acne e estrias, porém é aplicada com outras finalidades, como: drug delivery, tratamento de envelhecimento, flacidez cutânea e calvície.

As cicatrizes de acnes podem ser tratadas por IPCA para estimular a produção de colágeno e propiciar uma aparência mais estética. Para tanto, foi realizado um estudo com seis voluntários com idade média de 26,6 anos e que fizeram uso de isotretinoína oral antes do procedimento, com dose-alvo entre 120 e $150 \mathrm{mg} / \mathrm{kg}$. O IPCA foi realizado, no mínimo, seis meses após o término do tratamento isotretinoína oral e não faziam mais uso de medicação sistêmica. Ao exame físico foi constado a presença de cicatrizes de acne, sobretudo, nas regiões malar e temporal. O procedimento consistiu em antissepsia com solução alcoólica de clorexidina a $2 \%$, seguida de anestesia tumescente e aplicado o IPCA com agulhas de $2,5 \mathrm{~mm}$. Posteriormente, foi realizado o curativo oclusivo com associação de clobetasol e neomicina e trocado após 24 horas. IPCA proporcionou uma excelente resposta ao tratamento das cicatrizes de acne, com melhora da textura da pele e amenização das cicatrizes, pois a técnica permitiu a liberação de citocinas, fatores de crescimento, angiogênese, com produção final de colágeno tipo I (Lima et al., 2016).

Um estudo do tipo quase experimental, estudo de caso individual, com apenas um voluntário foi desenvolvido. Objetivou-se comprovar a eficácia da técnica de microagulhamento realizado através de roller associado com uma formulação cosmética em cicatrizes de acne na face. O participante foi avaliado por fotografias, questionário de satisfação e escala da dor. Foram aplicadas três sessões a cada 21 dias e como resultado ocorreu à redução das cicatrizes de acne, diminuição da oleosidade, melhora da textura facial e aumento da autoestima (Staub \& Machado, 2017). 
Há diversos cosméticos que podem ser utilizados para controlar a oleosidade e tratar a pele acneica. Uma boa proposta de tratamento pode ser o emprego de um sabonete normalizador; uma loção tônica adstringente; máscara para controle da oleosidade, secativa, anti-inflamatória e cicatrizante; um sérum secativo ou oil control; e um bom fotoprotetor. Os cosméticos podem ser utilizados em associação com os recursos fotoeletroterapêuticos.

Há princípios ativos que podem está presente nos cosméticos para se obter resultado no tratamento da acne, como por exemplo: ácido salicílico: esfoliante, antifúngico e antisséptico; acetilmetionato de zinco: seborregulador, microbicida, renovação celular, cicatrizante e proteção antirradicalar; ácido lactobiônico: antioxidante, hidratante, cicatrizante; enxofre bio-solúvel: secativo; extrato de aloe vera: antisséptico, antiinflamatório, cicatrizante, hidratação; extrato de hamamelis: adstringente, descongestionante, antisséptico e antisseborréico; extrato de pepino: hidratante, cicatrizante, antieritema e antiprurido; glucona lactona: desobstrução dos poros; ácido lático: hidratante, antimicrobiano, regulador do $\mathrm{pH}$, esfoliante e clareador da pele; ácido lactobiônico: cicatrizante, antioxidante, hidratante, rejuvenescedor, desobstrui os poros; melaleuca: antimicrobiano; niacinamida: anti-inflamatório, clareador, antiglicante; óxido de zinco: adstringente, antisséptico, secativo e anti-inflamatório; PCA Zinco: função seborregulador, antisséptico, anti-inflamatório; salicilato de dimetilsilanodiol: queratolítico, anti-inflamatório, antiedema; triclosan: antisséptico. Esses ativos estão presentes na maioria dos cosméticos para tratar a acne e controlar a oleosidade.

\section{Considerações finais}

A acne é uma doença prevalente e comum em adolescentes, embora possa persistir no adulto. Ela pode gerar impactos psicológicos e estéticos, além de poder deixar cicatrizes. Portanto, o tratamento precoce se faz necessário para manter a pele saudável ou reduzir as sequelas.

Estudos recentes reclassificaram a bactéria Propionibacterium acnes para Cutibacterium acnes e este fato pode ter repercussões sobre as condutas terapêuticas, principalmente sobre os medicamentos e cosméticos. E se postulou que o processo inflamatório está presente desde o início da doença, mas se mantém o conceito de quatro fatores básicos explicam a fisiopatologia da acne, são eles: hiperplasia das glândulas sebáceas e produção excessiva de sebo; hiperqueratinização do folículo pilossebáceo; colonização bacteriana; e inflamação e resposta imunológica.

A acne pode ser classificada quanto ao grau de gravidade de acordo com suas características em cinco graus. O esteticista pode intervir nos dois primeiros graus sem acompanhamento médico e, para tanto, ele possui um arsenal terapêutico que envolve recursos fotoeletroterapêuticos e cosméticos. Quando esse arsenal é corretamente empregado pode trazer benefícios significativos, tanto no tratamento da acne quanto no tratamento das cicatrizes acneicas.

\section{Agradecimentos}

Agradecemos a Revista PubSaúde pelo incentive a publicação e divulgação de estudos científicos.

\section{Referências}

Agostinho, M. R., Katz, N., Gomes, K. W., Souza, T. S. D., Martins, A. C. M., Marenco, G. N., \& Roman, R. 2017. TeleCondutas Acne. Faculdade de Medicina - Programa de Pós-Graduação em Epidemiologia Telessaúde. Rio Grande do Sul, RS: UFRGS.

Bagatin, E., Freitas, T. H. P., Rivitti-Machado, M. C., Machado, M. C. R., Ribeiro, B. M., Nunes, S. \& Rocha, M. A. D. D. 2019. Adult female acne: a guide to clinical practice. Anais Brasileiros de Dermatologia, 94(1), 6275. doi: 10.1590/abd1806-4841.20198203

Bessa, V. A. L. 2019. A proficuidade da alta frequência nos tratamentos estéticos e terapêuticos. Revista Científica Multidisciplinar Núcleo do Conhecimento, 7(6), 116-139. doi: 10.32749/nucleodoconhecimento.com.br/saude/tratamentos-esteticos

Borges, F. S., \& Scorza, F. A. 2016. Terapêutica em estética: conceitos e técnicas. São Paulo, SP: Phorte.

Costa, I., \& Velho, G. M. C. C. 2018. Acne Vulgar no Adulto. Revista da Sociedade Portuguesa de Dermatologia e Venereologia, 76(3), 299-312. doi: 10.29021/spdv.76.3.953

Dréno, B., Pécastaings, S., Corvec, S., Varaldi, S., Khammari, A., \& Roques, C. 2018. Cutibacterium acnes (Propionibacterium acnes) and acne vulgaris: a brief look at the latest updates. Journal of the European Academy of Dermatology and Venereology, 32 (2), 5-14. doi: 10.1111/jdv.15043 
Goel, A., \& Gatne, V. J. 2017. Journal of Cosmetic Dermatology, 16(2), 186-192. doi: 10.1111/jocd.12311

Hession, M. T., \& Graber, E. M. 2015. Atrophic acne scarring: a review of treatment options. The Journal of Clinical and Aesthetic Dermatology, 8(1) 50. doi: 10.18295/squmj.2016.16.02.004

Kaminaka, C., Furukawa, F., \& Yamamoto, Y. 2016. Long-Term Clinical and Histological Effects of a Bipolar Fractional Radiofrequency System in the Treatment of Facial Atrophic Acne Scars and Acne Vulgaris in Japanese Patients: A Series of Eight Cases. Photomedicine and Laser Surgery, 34(12), 657-660. doi: 10.1089/pho.2016.4116

Lima, C. N., Santana, L., Nascimento Pereira, D., Vasconcellos, J. B., Carvalho Lacerda, V., \& Vasconcelos, B. N. 2016. Microagulhamento no tratamento de cicatrizes atróficas de acne: série de casos. Surgical \& Cosmetic Dermatology, 8(4), 63-66. doi: 10.5935/scd1984-8773.2016831860

Martelli, A. 2016. Microcorrente no processo de cicatrização: revisão da literatura. Archives of Health Investigation, 5(3), 134-139. doi: 10.21270/archi.v5i3.1316

Miot, H. A., Penna, G. D. O., Ramos, A. M. C., Penna, M. L. F., Schmidt, S. M., Luz, F. B., ... Sanches Junior, J. A. 2018. Profile of dermatological consultations in Brazil (2018). Anais Brasileiros de Dermatologia, 93(6), 916-928. doi: 10.1590/abd1806-4841.20188802

Oaigher, K. A., \& Blanco, P. H. M. 2016. Efeitos da radiofrequência na derme e tela subcutânea. Revista UNINGÁ. Disponível em: <http://revista.uninga.br/index.php/uninga/article/view/1299>. Acesso em: 14 out. 2019.

Pei, S., Inamadar, A. C., Keshavmurthy, A. A., \& Tsoukas, M. M. 2015, May-Jun. Light-based therapies in acne treatment. Indian Dermatol Online J, 6(3), 145-157. doi: 10.4103/2229-5178.156379

Ribeiro, B. M., Almeida, L. M. C., Costa, A., Francesconi, F., Follador. I., \& Neves, J. R. 2015. Etiopatogenia da acne vulgar: uma revisão prática para o dia a dia do consultório de dermatologia. Surgical And Cosmetic Dermatology, 7(3), 20-26. doi: 10.5935/scd1984-8773.2015731682

Scholz, C. F., \& Kilian, M. 2016. The natural history of cutaneous propionibacteria, and reclassification of selected species within the genus Propionibacterium to the proposed novel genera Acidipropionibacterium gen. nov., Cutibacterium gen. nov. and Pseudopropionibacterium gen. nov. International Journal of Systematic and Evolutionary Microbiology, 66(11): 4422- 4432. doi: 10.1099/ijsem.0.001367

Silva, J. A. C., \& Pereira, P. C. 2018. Avaliação e tratamento estético da acne vulgar. Revista Científica da FEPI, $5(1)$.

Staub, J. D., \& Machado, G. R. 2017. Microagulhamento associado com formulação cosmética em cicatrizes de acne na face. Anais (VIII Salão de Ensino e Extensão da Unisc). Rio Grande do Sul, Santa Cruz do Sul.

Szabó, K., Erdei, L., Bolla, B. S., Tax, G., Bíró, T., \& Kemény, L. 2017. Factors shaping the composition of the cutaneous microbiota. British Journal of Dermatology, 176(2), 344-351.

Tan, A. U., Schlosser, B. J. \& Paller, A. S. 2018. A review of diagnosis and treatment of acne in adult female patients. International Journal of Women's Dermatology, 4(2): 56-71. doi: 10.1016/j.ijwd.2017.10.006

\section{Minicurrículos}

Vicente Alberto Lima Bessa. Graduado em Fisioterapia (1992) pela Universidade Castelo Branco. Tecnólogo em Estética e Cosmética pelo Centro Universitário Celso Lisboa (2018), especialista em Fisioterapia Dermatofuncional pela Faculdade Unyleya (2019), atuando nos seguintes temas: estética corporal, estética facial, estética masculina e terapia capilar. Atualmente é professor no Centro Universitário Celso Lisboa.

Maria Fátima de Sousa Bessa. Graduada em Educação Física pela Universidade Castelo Branco (1989), graduada em Fisioterapia pela Universidade Castelo Branco (1996), especialista em Ginástica Médica pela Universidade Castelo Branco (1993) e mestra em Ciência da Motricidade Humana pela Universidade Castelo Branco (2000), foi professora nos cursos de Fisioterapia e Educação Física da Universidade Castelo Branco e do Centro Universitário Moacyr Sreder Bastos, professora da Prefeitura de Duque de Caxias e professora da Prefeitura do Rio de Janeiro, atuando principalmente nos seguintes temas: estética corporal, estética facial e psicomotricidade.

Vanessa Teixeira Paula Moraes. Graduada em Estética e Cosmética pela Universidade do Grande Rio - Prof. José de Souza Herdy (2012), especialista em Cosmetologia Aplicada pela Universidade Estácio de Sá (2014), 
especialista em MBA Estética Clínica pela Universidade do Grande Rio - Prof. José de Souza Herdy (2016), especialista em Docência Inovadora do Ensino Superior pelo Centro Universitário Celso Lisboa (2018), atuou como professora de práticas (preceptora) de estética da Universidade do Grande Rio, palestrante em cursos e workshop e atualmente é professora no Centro Universitário Celso Lisboa. Tem experiência na área de Bioética, com ênfase em Tecnólogo em Estética

Como citar: Bessa, V.A.L., Bessa, M.F.S., Moraes, V.T.P. 2020. Tratamento Estético para Acne Vulgar. Pubsaúde, 3, a015. DOI: https:// dx.doi.org/10.31533/pubsaude3.a015

Recebido: 02 nov. 2019.

Revisado e aceito: 18 mar. 2020.

Conflito de interesse: os autores declaram, em relação aos produtos e companhias descritos nesse artigo, não ter interesses associativos, comerciais, de propriedade ou financeiros que representem conflito de interesse.

Licenciamento: Este artigo é publicado na modalidade Acesso Aberto sob a licença Creative Commons Atribuição 4.0 (CC-BY 4.0). 